\title{
The Effects of Reading Engagement on Literacy Achievement for Elementary Students
}

\author{
Meredith M. McClanahan ${ }^{1}$, Leslie S. Ennis ${ }^{1} \&$ Peggy H. Connell ${ }^{1}$ \\ ${ }^{1}$ Department of Educational Leadership, Samford University, Birmingham, AL, USA \\ Correspondence: Peggy H. Connell, Department of Educational Leadership, Samford University, 800 Lakeshore \\ Drive, Birmingham, AL 35229, USA. Tel: 205-726-2479.
}

Received: June 22, 2016

Accepted: July 6, 2016

Online Published: July 28, 2016

doi:10.20849/aes.v1i2.52

URL: http://dx.doi.org/10.20849/aes.v1i2.52

\begin{abstract}
Since reading achievement is a determining factor for academic success, children who struggle with reading often continue to struggle throughout their school careers. The purpose of this study was to compare the reading gain scores of fourth and fifth grade students at an elementary school in northeast Alabama to the quantity of their extracurricular reading activities, controlling for gender, ethnicity, and socioeconomic status (SES). Over a 20 -week period, the researcher utilized a daily reading log as the instrument to determine the amount of students' outside-of-school reading time engagement. The results of a factorial ANOVA indicated that the amount of out-of-school reading times did not significantly increase their gain scores on the STAR reading benchmark tests. This was true for gender, socioeconomic status, and race. The results have implications for utilization of out-of-school reading requirements.
\end{abstract}

Keywords: reading engagement, parent involvement, struggling reader, achievement

\section{Introduction}

According to Reading is Fundamental (RIF) (2014), 33\% of fourth-grade students scored at or below the base level score on the 2009 National Assessment of Educational Progress (NAEP) reading test. However, fourth graders who reported reading for fun on a daily basis scored on average 3\% higher on the NAEP assessment. FACE (2013) has reported similar results: Students who read and have access to books and literacy programs tended to have greater achievement in reading. The National Endowment for the Arts (2007), also, found a strong correlation between daily reading and higher academic achievement. Unfortunately, "Americans, especially younger Americans, read less, [and] they read less well. Because they read less well, they have lower levels of academic achievement". (National Endowment for the Arts, 20007, p. 5)

\subsection{Purpose}

To correct the reading deficit, struggling readers must spend substantial amounts of time actually reading (Miller, 2009). Unfortunately, struggling readers often received less exposure to text due to increased pull-out time from the regular classroom. While the pull-out time was designed to remedy a reading deficit; missing regular grade-level instruction resulted in a further decline in reading achievement (Miller, 2009). Therefore, educators have explored strategies outside the school day to encourage students to read.

\section{Reading Engagement Strategies}

\subsection{Parental Involvement}

Some researchers (e.g., Cheung \& Pomerantz, 2012; Education Research Center, 2004; Shiffman, 2011; Vellymalay, 2012) found that increased parental involvement is one way to encourage reading engagement for elementary students. According to Bartel (2010), children learned and achieved at higher levels when parents were active in their children's learning paths. However, the focus of the parental involvement was critical to maximize the benefits. According to Bonci, Mottram, and McCoy (2010), the degree and amount of time parents spent reading aloud to their children was a contributing factor to students' success.

\subsubsection{Barriers to Parental Involvement}

While there is a consensus of the benefits of parental involvement in student learning, engaging parents in a child's education can result in a struggle (Shiffman, 2011). However, since parent involvement "has been 
associated with better student attendance, higher math and reading scores, higher graduation rates, and less grade retention" (Larocque et al., 2011, p. 117), recognizing strategies to improve engagement is an imperative. Researchers (e.g., Bartel, 2010; DePlanty, Coulter-Kern, \& Duchane, 2007; Dobson, 2001; Hornby \& Lafaele, 2011; Larocque, Kleiman, \& Darling, 2011; Vellymalay, 2012) identified and categorized numerous barriers to increasing parental involvement: environmental factors, parental perceptions, and knowledge.

\subsubsection{Environmental Factors}

Environmental factors that contribute to a lack of parental involvement include socio-economic status (SES), level of education, marital status, number of children, gender, and ethnicity. According to Vellymalay (2012) and Bartel (2010), one of the most influential factors was parents' levels of SES. Parents from lower SES were less likely to engage in their children's academic activities than parents from middle and high SES. Factors that frequently contributed to parents' low SES included limited education level, single parent, and number of children in the home (Hornby \& Lafele, 2011). Dobson (2001) noted the changing role of mothers as more women sought careers outside the home resulted in less availability for involvement in their children's academics and extracurricular activities. Furthermore, changing demographics brought a variety of cultures to schools' student bodies, while the majority of the teachers' demographics remained white and middle SES (Larocque, Kleiman, \& Darling, 2011). The changing diversity of the student bodies created barriers and misunderstandings of differing customs.

\subsubsection{Parental Perceptions and Knowledge}

Another contributing factor affecting the level of parental involvement was parents' perceptions about school (Hornby \& Lafaele, 2011). Some of those perceptions included: a perceived lack of effort from the school or teacher, an environment that seemed unwelcoming, a lack of parent confidence pertaining to the benefits of participation, or negative personal experiences. Whitaker and Hoover-Dempsey (2013) agreed that some parents tended to have negative perceptions about schools and their own role in involvement. The power of creating a welcoming school environment generated the difference in the amount of parental involvement. Moreover, DePlanty et al. (2007) identified a need to educate parents about the benefits and the methods of involving themselves in their child's academic career.

\subsection{Extracurricular Activities}

In addition to parental involvement, another stimulus to motivate reading engagement for elementary students is participation in extracurricular reading programs. According to the Education Research Center (2004), after-school programs often create a safe and supervised avenue for children with the added benefit of academic support. Fiore and Roman (2010) studied the benefits of summer and school-year reading programs offered by public libraries. "Students who take part in their local library's summer reading program significantly improve their reading skills. In fact ... kids who participate in these programs are 52 Lexile points ahead of their peers who do not" (Fiore \& Roman, 2010, para. 2). Furthermore, participation in a library reading program can increase students' motivation to read, build confidence in their reading abilities, and assist in the development of a positive attitude toward reading.

\subsection{Private Tutoring}

Private tutoring is another method used to increase reading engagement (Dang \& Rogers, 2008). After the passage of the No Child Left Behind Act of 2001, the tutoring industry increased from a five-billion-dollar industry to an eight-billion-dollar industry (Nelson-Royes, 2013). The one-on-one setting with a tutor afforded more individualized instruction directly tailored to students' needs because "every student has the ability to learn, but some students have different learning styles" (Nelson-Royes \& Reglin, 2011, p. 112).

\subsection{Summary of Research}

Research establishing a correlation between the amount of extra curricula reading, through parent involvement, extracurricular activities, and private tutoring is well documented throughout the literature. However, the type and focus of parental engagement determines the degree of students' academic success. Additionally, educators often encounter barriers to increasing parental involvement including environmental factors, parental perception, and knowledge.

\section{Methods}

\subsection{Hypotheses}

This study analyzed the effects of an extracurricular reading activity on fourth- and fifth-grade students' reading achievement by students' gender, ethnicity, and SES. The following null hypotheses guided the study. 
1. There is no statistically significant difference in the level of students' extracurricular reading (low level, average level, high level) and their STAR reading gain scores.

2. There is no statistically significant difference in students' gender and their STAR reading gain scores.

3. There is no statistically significant difference in students' SES and their STAR reading gain scores.

4. There is no statistically significant difference in students' ethnicity and their STAR reading gain scores.

5. There is no statistically significant interaction between the level of students' extracurricular reading (low level, average level, high level) by gender, by SES, by ethnicity and their STAR reading gain scores.

\subsection{Research Design}

The researchers received approval from their university's Institutional Review Board to conduct the study and used an ex-post facto design since the research occurred without interference from the researcher. According to Silva (2010), this type of design is appropriate to investigate hypotheses when true experimental designs cannot be implemented. The independent variables were nominal level data and included: extracurricular reading engagement (low, average, high), gender (males, females), SES (high, low), and ethnicity (White, Black, Other). The dependent variable, STAR reading gain scores, was interval level data.

\subsection{Data Analysis}

The researcher used SPSS 19.0 to analyze the data. The researchers used a factorial ANOVA to investigate the null hypotheses at the .05 significance level. The researcher used Levene's Test to test the homogeneity of variance assumption. The students' extracurricular reading times provided definition for the three levels of reading engagement: low $=0-600$ minutes; average $=601-1,200$ minutes; and high $=1,201$ or more minutes. Enrollment in the free or reduced lunch program formed the basis for determining students' SES levels: not enrolled $=$ high and enrolled $=$ low. See Table 1 for the research design outline.

Table 1. Research design

\begin{tabular}{llrr}
\hline \multicolumn{2}{c}{ Value Label } & N & \%ile \\
\hline Reading Level & Low Level & 153 & $39 \%$ \\
\hline & Average Level & 136 & $34 \%$ \\
\hline Total & High Level & 108 & $27 \%$ \\
\hline Gender & & $\mathbf{3 9 7}$ & $50 \%$ \\
\hline & Males & 197 & $50 \%$ \\
\hline Total & Females & 200 & \\
\hline Race & & $\mathbf{3 9 7}$ & $77 \%$ \\
\hline & White & 307 & $14 \%$ \\
\hline & Black & 54 & $9 \%$ \\
\hline Total & Other & 36 & $29 \%$ \\
\hline SES & & $\mathbf{3 9 7}$ & $71 \%$ \\
\hline & Free/Reduced & 117 & \\
\hline Total & Full Pay & 280 & $\mathbf{3 9 7}$ \\
\hline
\end{tabular}

\subsection{Participants}

The population included students enrolled in a public elementary school in northeast Alabama. The school included grades three through five with a total student population of 602 . The racial composition was $76 \%$ White, $13 \%$ African-American, and $11 \%$ other ethnicities with $29 \%$ enrolled in the free or reduced lunch program and $71 \%$ not enrolled. The staff included 12 reading teachers, $90 \%$ White and $10 \%$ African-American.

Researchers used a convenience sampling method because they had access to the data. According to Creswell (2012), this is an appropriate method if "the sample can provide useful information for answering questions and hypotheses" (p. 146). The sample consisted of 195 fourth graders and 202 fifth graders for a total of 397 students. Included in the sample were 197 males and 200 females; 307 White students, 54 African-American students, and 36 other ethnicities; 117 students enrolled in the free or reduced lunch program and 280 students not enrolled. 
Staffing included eight reading teachers, $90 \%$ White and $10 \%$ African-American.

\section{Results}

Null hypothesis 1: There was no significant difference in the level of students extracurricular reading (low level, average level, high level) and their STAR reading gain scores, $F(2,362)=.12, p=.89$.

Null hypothesis 2: There was no significant difference in gender and their STAR reading gain scores, $F(1,362)$ $=.08, p=.77$.

Null hypothesis 3: There was no significant difference in students' SES and their STAR reading gain scores, $F(1$, $362)=.32, p=.57$.

Null hypothesis 4: There was no significant difference in students' ethnicity and their STAR reading gain scores, $F(2,362)=1.52, p=.22$.

Null hypothesis 5: There was no significant interaction between STAR reading gain scores by extracurricular reading levels by gender by race by $\operatorname{SES}, F(3,362)=1.66, p=.18$.

The amount of minutes' students read outside-of-school did not significantly increase their gain scores on the STAR reading benchmark tests. This was true for males and females; Whites, African-Americans, and other races; and low SES and average/high SES.

\section{Discussion}

With these results, the researcher concluded that the volume of reading alone will not ensure that students will have higher gain scores compared to students who do not actively read as much volume. According to Colker (2007) "a home environment that encourages learning is more important to student achievement than the family's income, education level, or cultural background" (para. 2); therefore, reading alone may not increase students' reading gain scores, but perhaps the active role of a family member could ensure achievement. An interesting facet for future consideration is the impact on a student's reading achievement when a family member incorporated discussions with the outside-of-school reading material along with the child.

Alternately, several studies concluded that a student's outside-of-school reading engagement with parents may result in a negative experience (Rogers, Theule, Ryan, Adams, \& Keating, 2009). The researchers contended that parent involvement was positive or negative, depending upon the nature of the involvement. A supportive, encouraging environment from parents led to higher student achievement and positive attitudes toward education; however, a critical, intrusive approach toward involvement led to lower success and negative feelings toward school (Rogers et al., 2009).

The current study has several implications for educational theory, policy, and practice. The No Child Left Behind Act of 2001 asserts that the most influential and important teacher in a child's life is his parents (DePlanty et al., 2007). This requires the attention of educators since it is supported by federal dollars with the requirement of improving student achievement. Parents and teachers should consider carefully the factors at school and outside-of-school that effect reading gains, and implement beneficial programs accordingly. Furthermore, since parent involvement "has been associated with better student attendance, higher math and reading scores, higher graduation rates, and less grade retention," designing strategies to encourage parent involvement is critical (Larocque et al., 2011, p. 117).

Another implication for theory, policy, and practice is to identify and target the best teacher practices to ameliorate the lack of reading improvement based on the level of reading engagement. Should elementary schools adapt their curriculum to meet the needs of a changing society and changing familial designs? Whether parent participation in outside-of-school reading is a factor, schools must find the most effective models of reading engagement to directly affect reading achievement gains.

\section{Limitations and Recommendations}

One weakness of the study may include the difference in teacher encouragement of the completion of the reading logs and the parent participation in the outside-of-school reading engagement. Some teachers strongly encouraged the role of parent participation in at-home reading, while other teachers did not implement the reading logs as thoroughly. An additional weakness is the uncertainty of the researcher of the accuracy and honesty of participants when completing the reading logs.

A potential improvement to this study could include the provision of a directive for teachers to follow with a more specific and uniform set of guidelines for implementing and carrying out the reading log procedures. This uniformity may result in different findings for the current study. In addition, the reading logs need greater 
specificity of components to assist teachers with targeting strategies for optimal reading success.

The results of this study provide an introduction to future research possibilities of outside-of-school reading engagement and the effect of that engagement on reading achievement gains. First, other researchers may replicate the study using a more diverse sample population with higher levels of SES differences and race compilation. Second, other information possibly pertinent to the results of the study may include a child's living arrangements and the impact of those arrangements on out-of-school reading involvement. Possible arrangements could include a child living: in a single-parent home, two biological parent home, foster home, extended family member's home, homeless, or other situations. A third option for replicating this study could include specific teacher guidelines for implementing the reading $\log$ to fidelity. Professional development in outside-of-school reading engagement or teacher-designed parental reading involvement could ensure uniformity and clarity in the promotion of outside-of-school reading. In addition, teachers could more stringently monitor student choices for reading to confirm they are challenging themselves appropriately. Fourth, a longitudinal study from kindergarten until grade five could provide data on the effects of outside-of-school reading engagement to the reading gain scores on STAR benchmark tests or another comparable measuring assessment while tracking students who participate in after-school programs or summer library reading programs. A fifth option for future studies could include a qualitative study on this topic to identify differing perspectives of the students, teachers, and parents on reading engagement and its implementation.

\section{Summary}

In conclusion, this study informed the researcher that the amount of time that students read outside-of-school did not significantly increase their gain scores on the STAR reading benchmark test. This was true for males, females, whites, blacks, other races, low SES, average/high SES, and a combination of all the variables. For such a critical life skill as reading, researchers must continue to study students' reading practices and achievement to uncover possible strategies and practices that could affect students' growth in learning and achievement.

\section{References}

Bartel, V. B. (2010, July). Home and school factors impacting parental involvement in a title I elementary school. Journal of Research in Childhood Education, 24, 209.

Bonci, A., Mottram, E., \& McCoy, E. (2010). A review of the research evidence underpinning partners in literacy. National Literacy Trust.

Cheung, C. S., \& Pomerantz, E. M. (2012). Why does parents' involvement enhance children's achievement? The role of parent-oriented motivation. Journal of Educational Psychology, 104(3), 820-832. http://dx.doi.org/10.1037/a0027183

Colker, L. J. (2007, July 26). Family involvement: A key ingredient in children's reading success. Retrieved April 28, 2014, from http://www.education.com/reference/article/Ref_Family_Involvement/

Dang, H. A., \& Rogers, F. H. (2008). The growing phenomenon of private tutoring: Does it deepen human capital, widen inequalities, or waste resources? The World Bank Research Observer, 23(2), 161-200. http://dx.doi.org/10.1093/wbro/lkn004

Davies, S. C., \& Peltz, L. J. (2012). At-risk students in after-school programs: Outcomes and recommendations. Principal Leadership, 12-16.

DePlanty, J., Coulter-Kern, R., \& Duchane, K. A. (2007). Perceptions of parent involvement in academic achievement. Journal of Educational Research, 100(6), 361-367.

Dobson, J. (2001). Bringing up boys: Practical advice and encouragement for those shaping the next generation of men. Wheaton, Illinois: Tyndale House Publishers.

Education Research Center. (2004, August 3). Issues A-Z: After-school programs. Education Week. Retrieved from http://www.edweek.org/ew/issues/after-school-programs/

FACE. (2013). The life-enhancing benefits of reading in out-of-school programs. Family and community engagement and afterschool alliance 2013 issue brief. Retrieved from www.afterschoolalliance.org

Fiore, C., \& Roman, S. (2010). Summer reading programs boost student achievement, study says. School Library Journal.

Retrieved

from http://www.slj.com/2010/11/students/summer-reading-programs-boost-student-achievement-study-says/\#_

Hill, N. E., \& Taylor, L. C. (2004). Parental school involvement and children's academic achievement. Current Directions in Psychological Science, 13(4), 161-164. 
Homeroom: The official blog of the U.S. Department of Education. (2014, September 9). Summer Slide. Retrieved from http://www.ed.gov/blog/tag/summer-slide/

Hornby, G., \& Lafaele, R. (2011). Barriers to parental involvement in education: An explanatory Model. Educational Review, 63(1), 37-52.

Larocque, M., Kleiman, I., \& Darling, S. M. (2011). Parental involvement: The missing link in school achievement. Preventing School Failure, 55(3), 115-122. http://dx.doi.org/10.1080/10459880903472876

Miller, D. (2009). The book whisperer: Awakening the inner reader in every child. New York, NY: Scholastic Inc.

National Center on Response to Intervention. (2014). Screening tools. American Institutes for Research. Washington, D.C. Retrieved from http://www.rti4success.org/resources/tools-charts/screening-tools-chart

Nelson-Royes, A. M. (2013). Tutors can improve students' reading skills. Reading Improvement, 50(2), 48-53.

Nelson-Royes, A. M., \& Reglin, G. L. (2011). After-school tutoring for reading achievement and urban middle school students. Reading Improvement, 48(3), 105-117.

Reading is Fundamental (RIF). (2014, February 26). Literacy facts and stats. Retrieved from http://www.rif.org/us/about/literacy-facts-and-stats.htm

Rogers, M. A., Theule, J., Ryan, B. A., Adams, G. R., \& Keating, L. (2009) Parental involvement and children's school achievement: Evidence for mediating processes. Canadian Journal of School Psychology, 24(1), 34-57. http://dx.doi.org/10.1177/0829573508328445

Shiffman, C. D. (2011). Making it visible: An exploration of how adult education participation informs parent involvement in education for school-age children. Adult Basic Education and Literacy Journal, 5(3), 161-170.

Smith, L. (2011, December / 2012, January). Slowing the summer slide. The Resourceful School, 69(4), 60-63.

Turney, K., \& Kao, G. (2009). Barriers to school involvement: Are immigrant parents disadvantaged? The Journal of Educational Research, 102(4), 257-271.

Vellymalay, S. K. N. (2012). Parental involvement at home: Analyzing the influence of parents' socioeconomic status. Studies in Sociology of Science, 3(1), 1-6. http://dx.doi.org/10.3968/j.sss.1923018420120301.2048

Whitaker, M., \& Hoover-Dempsey, K. (2013). School influences on parents' role beliefs. The Elementary School Journal, 114(1), 73-99.

\section{Copyrights}

Copyright for this article is retained by the author(s), with first publication rights granted to the journal.

This is an open-access article distributed under the terms and conditions of the Creative Commons Attribution license (http://creativecommons.org/licenses/by/3.0/). 